\title{
Stability Analysis of the Mathematical Model on the Control of HIV/AID Pandemic in a Heterogenous Population
}

\author{
David Omale ${ }^{*}$, Saikat Gochhait ${ }^{2}$ \\ ${ }^{1}$ Mathematical Sciences Department, Kogi State University Anyigba, Kogi State (261), Nigeria \\ ${ }^{2}$ Symbiosis Institute of Telecom Management, Constituent of Symbiosis International: Deemed University, Pune 412115, India
}

Corresponding Author Email: saikat.gochhait@sitm.ac.in

https://doi.org/10.18280/ama_a.562-404

Received: 27 July 2018

Accepted: 2 March 2019

\section{Keywords:}

mathematical model, vaccine, condom, therapy, asymptotical stable

\begin{abstract}
HIV/AIDS is a dreaded disease which has over the year claimed the life of so many people both female and male, adult and children in the whole continents or the globe. The mathematical model on the control of HIV/AID control was formulated using, vaccine, condom, therapeutic dose and public health campaign. The Maple software was applied to obtain the Eigen values which validate the asymptotical unstable nature of the disease equilibrium position. The paper suggests with the appropriate use of condom for both female and male can help to reduce both the prevalence and incidence of the HIV/AIDs pandemic.
\end{abstract}

\section{INTRODUCTION}

The human immunodeficiency virus since discovery has caused a lot of havoc to the global community by weakening the person's immune system as it destroys the most important cells that fight diseases and infection in human body.

No effective cure exists right now against this disease, HIV, but with proper Medicare, HIV can be controlled. People are likely to get HIV more even because of many factors which includes; their sex partners, their risk behaviours, and where they live.

HIV can be transmitted through sexual behaviours and needle or syringe use. Only certain body fluids - blood, semen (cum), pre seminal fluid (pre cum), rectal fluids, vaginal fluids and breast milk from a person who has HIV can transmit HIV virus (CDC 2017). These fluids must come in contact with the mucous membrane or damage tissue or be directly injected into the blood stream (from the needle or syringe) for transmission to occur. These mucous membranes are found inside the rectum vagina, penis or mouth.

The number of new HIV infection has declined globally by $21 \%$ since the estimated peak of the epidemic in 1997, 2.1 million People were newly infected with HIV worldwide in 2017 (NACA). In some part of the world, particularly within sub Sahara Africa, between $15 \%$ to $28 \%$ of the population are living with HIV. According to Naresh et al. [1], the study of HIV/AIDS control dynamics has been of great interest to both applied mathematicians and biologists due to its universal threat to human existence. Mathematical model has been used in the study of HIV/AIDS control and treatment.

Yusuf and Benyah [2] presented a deterministic mode, for controlling the spread of HIV/AIDS. Gumel et al. [3] proposed a mathematical model for the dynamic of an infectious disease, a three dimensional model which assumed a non - linear incidence rate was quantitatively analysed to determine the stability of the equilibrium. Naresh et al. [1] also proposed non linear ordinary differential equation model to study the effect of vaccination on the spread of HIV/AID in a homogenously mixing population. $\mathrm{Wu}$ et al. [4] studied the impact of imperfect vaccine and their analysis showed that in a population of self interested individuals, there exists an overshooting of vaccine uptake level as the effectiveness of vaccination increases. The basic reproduction number of their model was calculated. Isaac et al. [5] presented a mathematical model of HIV/AIDS at the Techiman municipality of Ghana and recommended that HIV/AIDS education should be intensified.

Omale et al. [6] presented a well structured mathematical model for the control of HIV/AIDS using condom, vaccine, therapeutic doses with public health campaign in a heterogeneous population using $\left(\mathrm{SVHEII} \mathrm{I}_{2} A_{2} A A_{T}\right)$ model formulation. The model is well posed and invariant within a well feasible deterministic region.

Motivated by the above work, in this paper we consider the stability analysis of the model by looking at the local and global stability of the disease free equilibrium, and the basic reproduction number of the model. Some numerical simulations are also given.

\section{MATHEMATICAL MODEL FORMULATION}

The development of our model is based on the following assumptions, in Omale et al. [6] as,

(1) The diseases HIV/AIDS is killing continuously

(2) Individual who contact this disease will definitely die of the disease if untreated or on control drug.

(3) There is no medicine right now for total cure of this particular disease, therefore infected individual will live with the disease in his/her life time. Individual on HIV drug will remain on the drug forever.

(4) Individual who is faithful to the drug will not die of HIV/AIDS 
(5) There is no vaccine with $100 \%$ efficacy to prevent HIV/AIDS.

(6) The available vaccines are imperfect; and so the vaccine will wane with time.

(7) That not all the people within the sexually active population are willing to use condom whenever they have sex.

(8) There are no vertical transmissions of the diseases.

(9) That campaign reduces the rate of transmission; because those who are properly informed will reduce their exposure to infection whenever they meet any infectious opportunity.

Rate of infection $k$, the force of infection is given by

$$
k=\frac{n_{1} \beta_{1} I_{2}+n_{2} \beta_{2} A_{2}+n_{3} \beta_{3} A_{T}}{N}
$$

where,

$n=$ number of sex partners

$\beta_{1}=$ transmission rate from infectious individual not receiving treatment

$\beta_{2}=$ transmission rate from infectious individual receiving treatment

$\beta_{3}=$ transmission rate of AIDS individual who is undergoing therapy, (HAARTS)

In the force of infection $\beta_{1}>\beta_{2}>\beta_{3}$. This show that $\beta_{1}$ contribute much on the transmission of the infection due to the fact that they are not receiving treatment, so they are not protected, $\beta_{2}$ contribute much less on the transmission of the infection due to their HIV status, they have acquired HIV/AIDS but receiving treatment so their viral load will be significantly reduced, unless if they desist from taking their daily pills. $\beta_{3}$ is expected to contribute least to the infection, since they just acquired the full virus and are aware of the AIDS status and they are receiving the daily therapy. There is natural death rate $(\mu)$ in the whole compartments, but there is an HIV/AIDS induced death rate in the $(A)$ and $\left(A_{2}\right)$ classes. $(A)$ and $\left(A_{2}\right)$ are the same if proportion of $(A)$ class stop receiving treatment, Omale et al. [6].

Table 1. State variable of the HIV/AIDS with control strategies

\begin{tabular}{|c|c|}
\hline$S(t)$ & Number of susceptible at time $t$ \\
\hline$V(t)$ & Number of preventive vaccinated individual at time $t$ \\
\hline$H(t)$ & Number of susceptible that are condom users at time $t$. \\
\hline$E(t)$ & Latent/exposed individuals at time \\
\hline$I(t)$ & $\begin{array}{l}\text { Infectious individuals at time } t \text { not receiving any } \\
\text { treatment }\end{array}$ \\
\hline$I_{2}(t)$ & $\begin{array}{c}\text { Number of infectious individuals who are undergoing } \\
\text { treatment }\end{array}$ \\
\hline$A(t)$ & Number of individuals with full blown AIDS. \\
\hline$A_{T}(t)$ & $\begin{array}{c}\text { Number or proportion of full blown AIDS who are } \\
\text { undergoing therapy. }\end{array}$ \\
\hline$A_{2}(t)$ & $\begin{array}{l}\text { Proportion of full blown AIDS who are not receiving the } \\
\text { therapy. }\end{array}$ \\
\hline
\end{tabular}

The total population at any time $t$ is given by

$$
\begin{gathered}
N(t)=S(t)+V(t)+H(t)+E(t)+I(t)+I_{2}(t) \\
+A_{2}(t)+A(t)+A_{T}(t)
\end{gathered}
$$

The population is homogeneously mixed and each susceptible individual has equal chance of acquiring HIV infection when the individual come in contact with an infectious individual [7].
The variables and parameters to be used in the model are as Table 1 and Table 2.

Table 2. Parameter descriptions

\begin{tabular}{cc}
\hline$\pi$ & Population recruited into the susceptible class. \\
\hline$P$ & $\begin{array}{c}\text { Proportion of susceptible recruited individual with lost } \\
\text { preventive vaccination }\end{array}$ \\
$\omega$ & Proportion of susceptible recruited individual that uses \\
condom
\end{tabular}

\section{EXISTENCE OF EQUILIBRIUM POINTS}

Let $E\left(s^{*}, v^{*}, h^{*}, e^{*}, i^{*}, i^{*}{ }_{1}, a^{*}, a^{*}{ }_{1}, a_{2}{ }^{*}\right)$ be the equilibrium point of normalized model system (1). The equilibrium points can be derived by setting the right hand side of (1) equal to zero, that is

$$
\begin{gathered}
\frac{d s^{*}}{d t}=\pi+\delta_{c}+ \\
\varepsilon h^{*}-\left(n_{1} \beta_{1} i+n_{2} \beta_{2} i_{2}+n_{3} \beta_{3} a_{2}\right) s^{*} \\
+\left(\theta+\delta_{2} c+p+\omega+\mu\right) s^{*}=0 \\
\frac{d v^{*}}{d t}=(p+\theta) v^{*}-\left(1-\theta_{1}\right)\left(n_{1} \beta_{1} i+n_{2} \beta_{2} i_{2}\right. \\
\left.+n_{3} \beta_{3} a_{2}\right) v^{*}+\delta_{1} c s^{*}-\mu v^{*}=0 \\
\frac{d h^{*}}{d t}=\left(\omega+\delta_{2} c\right) s^{*} \\
-(1-\varphi)\left(n_{1} \beta_{1} i+n_{2} \beta_{2} i_{2}\right. \\
\left.+n_{3} \beta_{3} a_{2}\right) h^{*}-(\varepsilon+\mu) h^{*}=0 \\
\frac{d e^{*}}{d t}=(1- \\
\varphi)\left(n_{1} \beta_{1} i+n_{2} \beta_{2} i_{2}+n_{3} \beta_{3} a_{2}\right) h^{*} \\
+\left(1-\theta_{1}\right)\left(n_{1} \beta_{1} i+n_{2} \beta_{2} i_{2}\right. \\
\left.+n_{3} \beta_{3} a_{2}\right) v^{*} \\
+\left(n_{1} \beta_{1} i+n_{2} \beta_{2} i_{2}+n_{3} \beta_{3} a_{2}\right) s^{*} \\
-(\phi+\mu) e^{*}=0 .
\end{gathered}
$$

$$
\begin{gathered}
\frac{d i^{*}}{d t}=\phi e^{*}+\left(1-\sigma_{1}\right) i_{2}-(\tau c+\eta e+\mu) i^{*}=0 \\
\frac{d i_{1}}{d t}=r_{1} c a-\left(\left(1-\sigma_{2}\right)+\mu\right) i_{1}=0
\end{gathered}
$$




$$
\begin{gathered}
\frac{d a^{*}}{d t}=\eta e i^{*}+\left(1-\sigma_{2}\right) a_{1}{ }^{*}-\left(r_{1} c+\alpha+r_{2}+\mu\right) a^{*} \\
=0 \\
\frac{d a_{2}}{d t}=r_{2} a-(\alpha+\mu) a_{2}=0 \\
\frac{d a_{1}}{d t}=\tau c i-\left(\left(1-\sigma_{1}\right)+\mu\right) a_{1}=0
\end{gathered}
$$

\section{EXISTENCEOF DISEASE FREE EQUILIBRIUM POINT (DFE)}

The disease free equilibrium of the normalized model system (1) is obtained by setting

$$
\begin{aligned}
\frac{d s^{*}}{d t}=\frac{d v^{*}}{d t}=\frac{d h^{*}}{d t} & =\frac{d e^{*}}{d t}=\frac{d i^{*}}{d t}=\frac{d i^{*}{ }_{2}}{d t}=\frac{d a^{*}}{d t} \\
& =\frac{d a^{*}}{d t}=\frac{d a^{*}}{d t}=\frac{d a^{*}{ }_{2}}{d t}=0
\end{aligned}
$$

\section{THE EFFECTIVE REPRODUCTION NUMBER}

The effective reproduction number $R_{0}$ of the systemis obtained by using the next generation operator method to assess the stabilities of the DFE and the endemic equilibrium $(E E)$ point and the computation of the Basic Reproduction Number is very essential. According to Dickman et al., the basic reproduction number is defined as the effective number of secondary infection caused by a typical infected individual during his/her entire period of infectiousness. This definition is given for the models that represent spread of infection in a population. It is obtained by taking the largest (dominant) Eigen value (Spectral radius) of;

$$
\left[\frac{\partial F_{i}\left(E_{0}\right)}{\partial X_{j}}\right]\left[\frac{\partial V_{i}\left(E_{0}\right)}{\partial X_{j}}\right]^{-1}
$$

where, $F_{i}$ is the rate of appearance of new infection in compartment $i$.

$V_{i}^{+}$is the transfer of individuals into compartment $i$.

$V_{i}^{-}$is the transfer of individual out of the compartment $i$ by all other means.

$E_{0}$ is the disease free equilibrium.

If the DFE is locally asymptotically stable, then the disease cannot invade the population, that is $R_{0}<1$ and if on the other hand, the infected individual in the population grows, that means the disease can spread fast in the population, then $R_{0}>1$. where, $G$ is given as,

$$
G=\frac{r n_{1} \beta_{1} S^{*} N k_{4}\left(k_{6} k_{5}-\tau c m_{3}\right)+r n_{2} \beta_{2} S^{*} \phi k_{6} N k_{4}+r n_{3} \beta_{3} S^{*} \tau c \phi N k_{4}}{N k_{4}^{2}\left(k_{6} k_{5}-\tau c m_{3}\right)}
$$

Substituting the values of the variables as in equation above, then we have

$$
G=\frac{r n_{1} \beta_{1}(\phi+\mu)\left[\left(\left(1-\sigma_{1}\right)+\mu\right)\left(\tau_{c}+\eta_{c}+\mu\right)-\tau_{c}\left(1-\sigma_{1}\right)\right]+r n_{2} \beta_{2} \tau_{c} \phi\left(1-\sigma_{1}+\mu\right)(\phi+\mu)+r n_{3} \beta_{3} \tau c \phi(\phi+\mu)}{(\phi+\mu)\left[\left(1-\sigma_{1}+\mu\right)\left(\tau_{c}+\eta_{c}+\mu\right)-\tau_{c}\left(1-\sigma_{1}\right)\right]}
$$

The basic reproduction number, which is given by the largest equation of the normalized model system (3) with vaccination strategies, condom usage, public health campaign and treatment, is given as in (25) above:

$G=R_{0}$.

$R_{0}$ measures the average number of new infections resulted by introducing one infected individual into the population of which are completely susceptible. Anderson (1) [8].

\section{LOCAL STABILITY OF DISEASE FREE EQUILIBRIUM POINT}

$$
\begin{aligned}
& \bar{\eta}_{1}=\left(\theta+\delta_{1} c+p+\omega+\mu\right), \bar{\eta}_{2}=(\delta+\mu), \bar{\eta}_{3}=(\varepsilon+\mu), \bar{\eta}_{4}=(\theta+\mu), \bar{\eta}_{5}=\left(\tau_{c}+\eta c_{3}+\mu\right) \\
& \overline{\eta_{6}}=\left(\left(1-\sigma_{1}\right)+\mu\right), \overline{\eta_{7}}=\left(\left(1-\sigma_{2}\right)+\mu\right), \overline{\eta_{8}}=(\alpha+\mu)
\end{aligned}
$$

Local stability of disease free equilibrium $E_{0}$ is obtained by the variational matrix $M_{0}$ of the normalized model system corresponding to $E_{0}$ as given below.

We set the systems by considering the normalized systems.

$$
\begin{gathered}
H_{0}=\frac{d s}{d t}, P_{0}=\frac{d v}{d t}, K_{0}=\frac{d h}{d t}, G=\frac{d e}{d t}, X=\frac{d i}{d t}, Y \\
=\frac{d i_{2}}{d t}, \\
Z=\frac{d a_{i}}{d t}, M=\frac{d a}{d t}, N=\frac{d a_{2}}{d t}
\end{gathered}
$$

This implies that where $\bar{\eta}_{i}$ are the eigenvalues
This follows that, since non ofl the eigenvalues of the characteristic equation have negative real parts, the disease free equilibrium $E_{0}$ is not locally asymptotically state in the region $\Omega$.

\section{ENDEMIC \\ EQUILIBRIUM AND \\ LOCAL STABILITY}

From the equilibrium of the normalized system (3), we equate the right hand to zero and with the Basic reproduction number $R_{0}$, where 
We can obtain the endemic equilibrium system of (3) $E^{*}=$ $\left(s^{*}, h^{*}, v^{*}, e^{*}, i^{*}, i_{2}{ }^{*}, a^{*}, a_{1}{ }^{*}, a_{2}{ }^{*}\right)$ Exists if $R_{0}>1$ and $\left(s^{*}, h^{*}, v^{*}, e^{*}, i^{*}, i_{2}{ }^{*}, a^{*}, a_{1}{ }^{*}, a_{2}{ }^{*}\right)$ satisfies the following

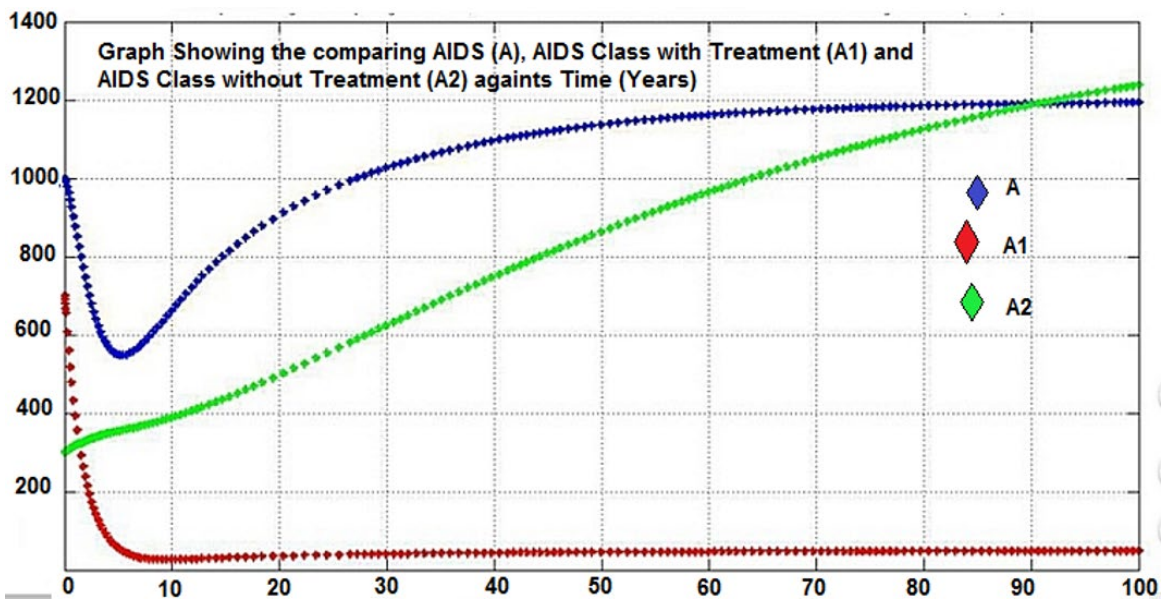

Figure 1. Comparism of aids class, aids class with treatment and without treatment

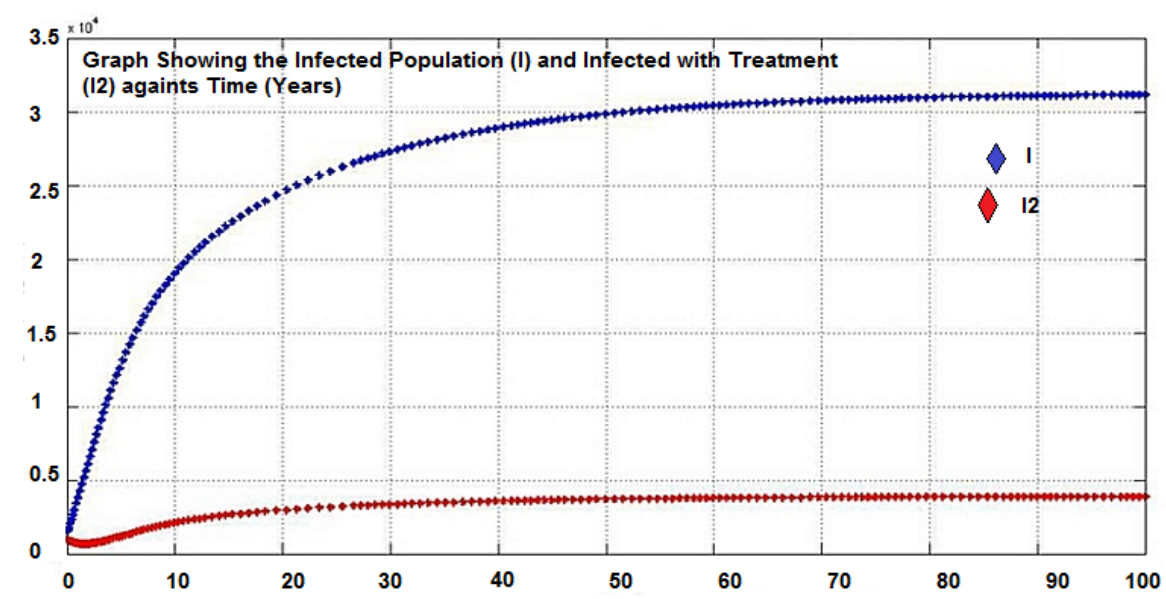

Figure 2. Comparism of infected class and infected class without treatment

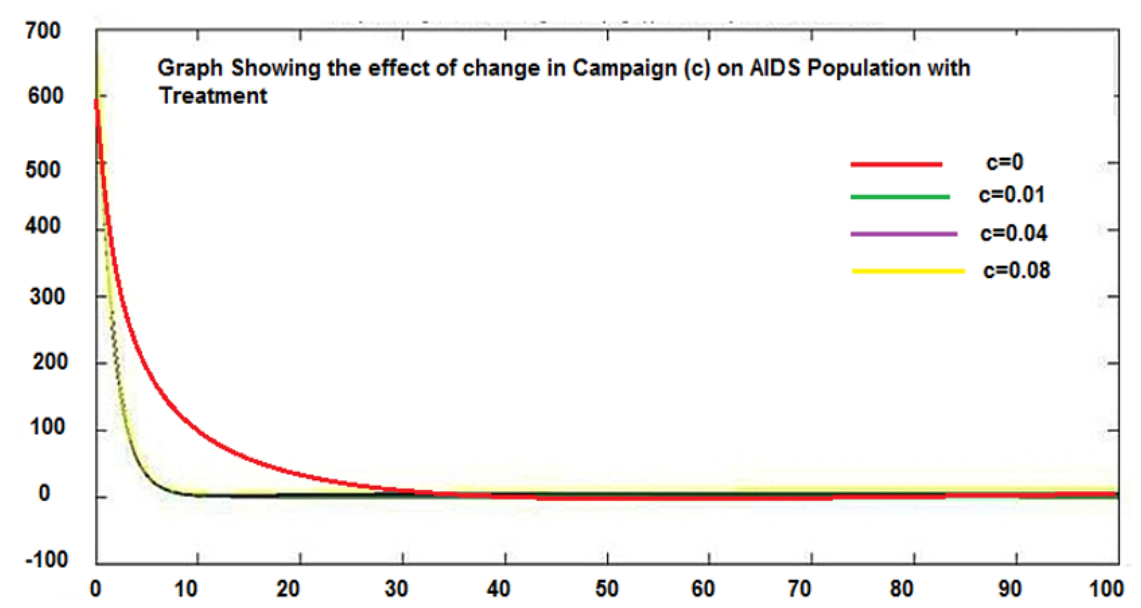

Figure 3. Effect of public health campaign on aids patient with treatment

The unique endemic equilibrium $E^{*}$ of the normalized model exists and is locally asymptotically stable if $R_{0}>1$ and unstable if $R_{0}<1$.
This show the interaction with various classes for more clear view. After a long period the AIDS with treatment rises above AIDS class without treatment indicating that the treatment has the power to prevent HIV/AIDS death. 
Figure 2 shows the comparism between infected class and infected class without treatment. The population of the infected class without treatment is always on increase due to the fact that those infected and are not taken any therapy consciously will be on the increase and eventually death but those infected may go for therapy and may not die of HIV/AIDS death, this may be the reason for a drop in the graph of the infected class below the infected class without treatment using the parameters value as described earlier on the initial condition.

The use of HAART reduces the viral load of AID patient who is taking therapy regularly. Therefore use of public health campaign on the use of therapy will reduce the effect of HIV/AIDS death within the population as we vary values of $\mathrm{c}$ from $c=0.00, c=0.01, c=0.04, c=0.08$ the increase in the public health campaign will to reduction in patient with HIV/AIDS with treatment.

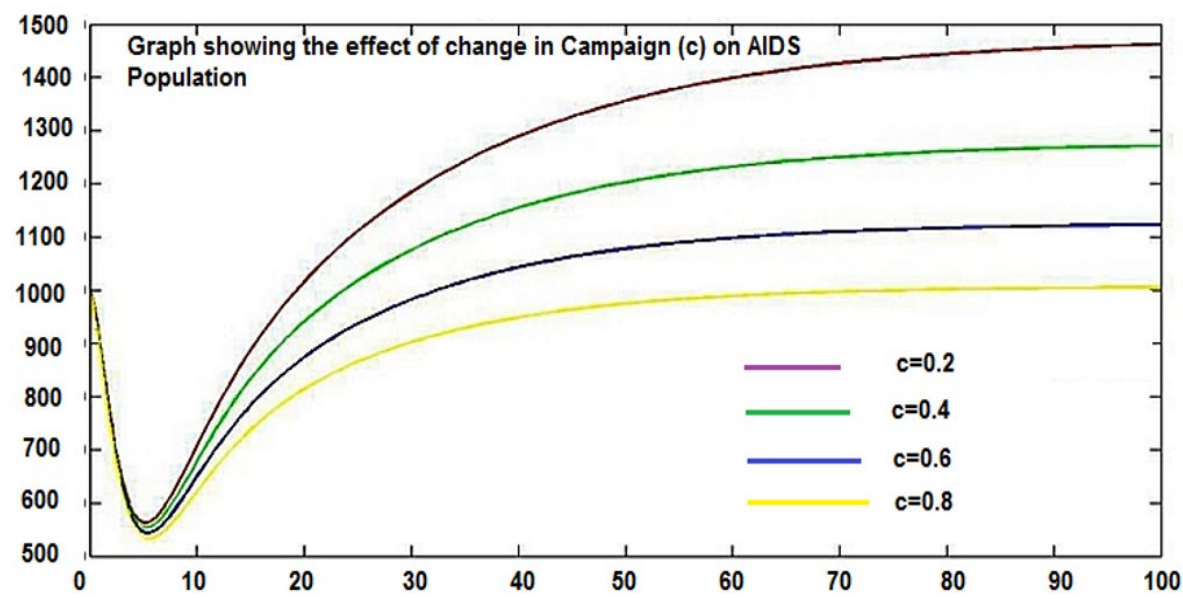

Figure 4. Effect of public health campaign on aids population without treatment

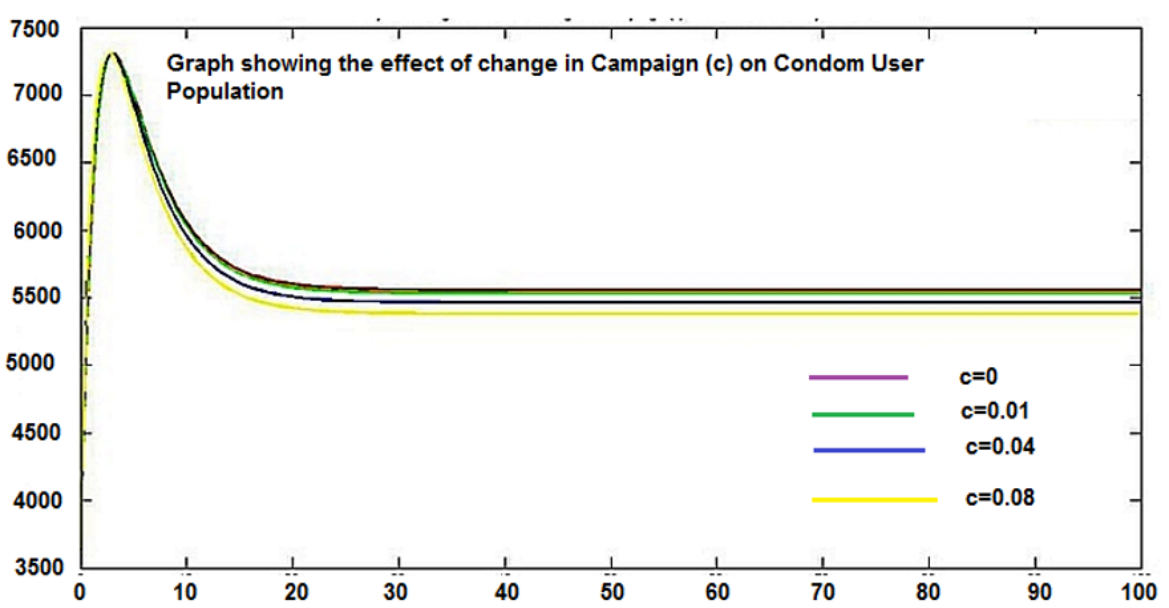

Figure 5. Effect of public health campaign on the use of condom

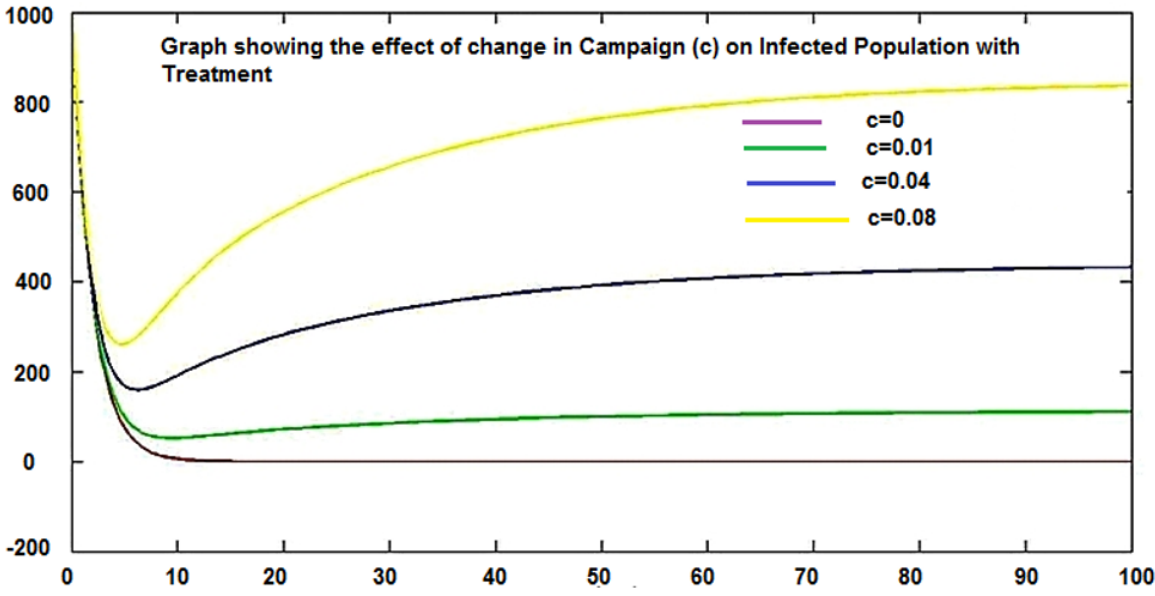

Figure 6. Variation on the change in public health campaign on infected population with treatment 
Figure 4 indicate that increase in public health campaign from $c=0.2, c=0.4, c=0.6, c=0.8$ will lead to a significant decline in the number of people who will adamantly refuse to present themselves for screening and eventually therapy as you can see above public health campaign will force people out of this class and attendant consequences.
Figure 5 shows the variation in public health campaign as $c=0.0, c=0.1, c=0.4, c=0.8$ indicating that increasing the public health education in the population on the need for anyone who may endure in legal or illicit sex to use condom will definitely reduce the number of people that will remain in this class for a long time after a period of 20 years using the parameter values

$$
\begin{aligned}
& \pi=2000, \delta_{2}=0.5, c=0.5, \varepsilon=0.10, r=0.25, k=0.5 \rho=0.01, \delta_{1}=0.45, \mu=0.02, \varphi=0.4, \theta_{1}=0.5, \\
& \phi=0.743, \tau=0.13, \eta=0.1, \sigma_{1}=0.08, \sigma_{2}=0.4, r_{1}=0.05, r_{2}=0.025, \alpha_{1}=0.45, \alpha_{2}=0.375, \\
& e=0.19
\end{aligned}
$$

Using the parameter values

$\pi=2000, \quad \delta_{2}=0.5, c=0.5, \quad \varepsilon=0.10, r=0.25, k=0.5, \rho=0.01$, $\delta_{l}=0.45, \quad \mu=0.02, \varphi=0.4, \quad \theta_{l}=0.5, \phi=0.743 \tau=0.13, \eta=0.1$, $\sigma_{l}=0.08, \sigma_{2}=0.4, r_{l}=0.05, r_{2}=0.025, \alpha_{l}=0.45, \alpha_{2}=0.375, e=0.19$

As seen above, if the public health campaign increase it will lead to significant increase in the number of those that will present themselves for therapy with the variation in public health education as $c=0.02$.

If we increase the public health campaign this will reduce the number of those to be infected, because with effective public health campaign (c), people will not go for vaccine or for condom use.

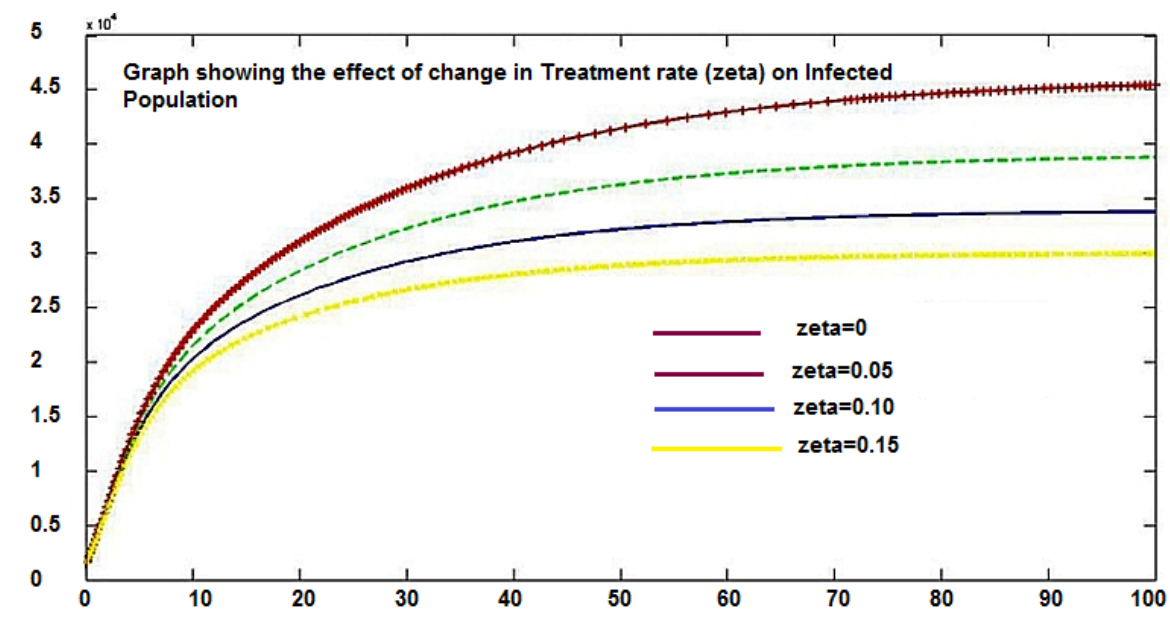

Figure 7. Variation on the change in public health campaign on infected population with treatment

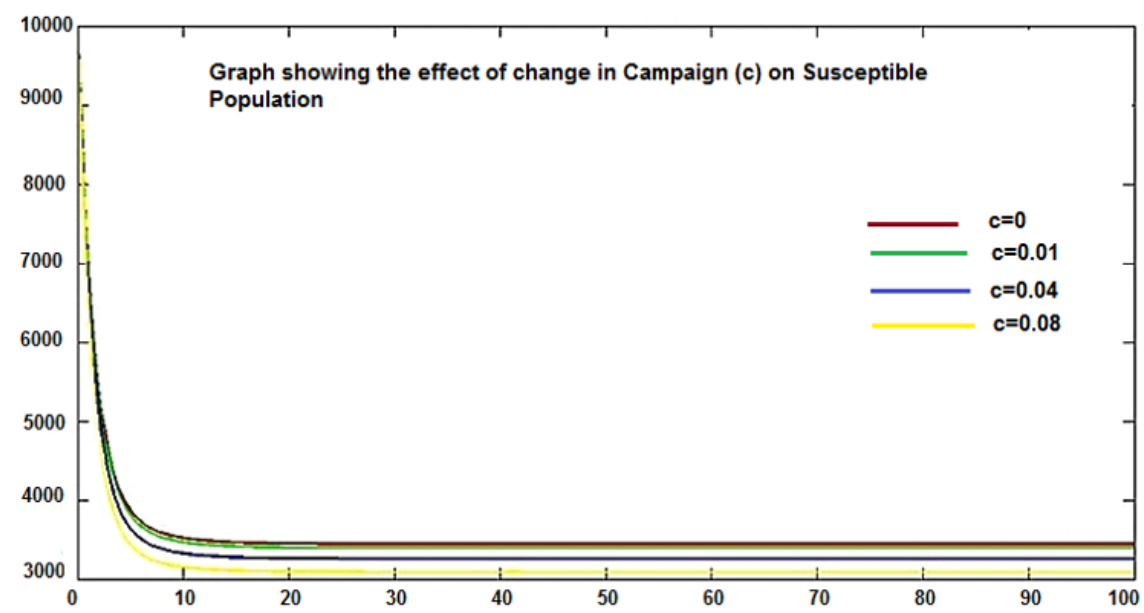

Figure 8. Effect of campaign on infected population

\section{CONCLUSION}

In this paper, HIV/AIDS epidemic model was considered in which a nonlinear incidence rate was introduced. The general dynamic of our model is determined by the study of the basic reproduction number $R_{0}$. Where the $R_{0}<1$, the disease free equilibrium is globally asymptomatically stable and when the
$R_{0}>1$, the unique endemic equilibrium is globally asymptomatically stable.

We finally suggest that the appropriate use of condom both by the female and male during sexual intercourse whether heterosexual or homosexual will combat the spread of HIV/AIDS within the population and sexual habits can reduce both the prevalence and incidence of the HIV/AIDS pandemic. 
Empower people infected and affected by HIV/AIDS through training, consulting and education to cope with the circumstances.

Develop standards and guidelines that can lead to the institutionalization of the best practices to mitigate the impact of AIDS

Ensure that prevention program are developed and targeted at vulnerable groups such as women and children adolescent and young adult, sex workers, long distance commercial vehicle driver, prison inmate's migrant labour etc.

\section{REFERENCES}

[1] Naresh, R., Tripathi, A., Sharma, D. (2011). A nonlinear AIDS epidemic model with screening and time delay. Applied Mathematics and Computation, 217(9): 44164426. https://doi.org/10.1016/j.amc.2010.10.036

[2] Yusuf, T.T., Benyah, F. (2012). Optimal strategy for controlling the spread of HIV/AIDS disease: a case study of South Africa. Journal of Biological Dynamics, 6(2): 475-494. https://doi.org/10.1080/17513758.2011.628700

[3] Gumel, A.B., Moghadas, S.M., Mickens, R.E. (2004). Effect of a preventive vaccine on the dynamics of HIV transmission. Communications in Nonlinear Science and Numerical Simulation, 9(6), 649-659. https://doi.org/10.1016/S1007-5704(03)00024-8
[4] Wu, B., Fu, F., Wang, L. (2011). Imperfect vaccine aggravates the long-standing dilemma of voluntary vaccination. PloS One, 6(6): e20577. https://doi.org/10.1371/journal.pone.0020577

[5] Adu, I.K., Boah, D.K., Eduafo, S. (2015). Mathematical model of HIV/AIDS at Techiman municipality, Ghana. International Journal of Mathematics and Statistics Studies, 3: 1-10.

[6] Omale, D., William, A. (2018). Nonlinear analysis of the HIV/AIDS control pandemic model within a heterogeneous population. International Research Journal of Advanced Engineering and Science, 3(4): 4348

[7] Omale, D., Gochhait, S. (2018). Analytical solution to the mathematical models of HIV/AIDS with control in a heterogeneous population using Homotopy Perturbation Method (HPM). AMSE journals-AMSE IIETA-Series: Advances $\quad$ A, 20-34. https://doi.org/10.18280/ama_a.550103

[8] Anderson, R.M., Swinton, J., Garnett, G.P. (1995). Potential impact of low efficacy HIV-1 vaccines in populations with high rates of infection. Proceedings of the Royal Society of London. Series B: Biological Sciences, 261(1361): 147-151. https://doi.org/10.1098/rspb.1995.0129 